\title{
A Game of Two Elderly Care Facilities: Competition, Mothballing Options, and Policy Implications
}

\author{
Congcong Wang, ${ }^{1,2}$ Yingxue Zhao, ${ }^{1}$ and Rongda Chen ${ }^{1,2}$ \\ ${ }^{1}$ School of Finance, Zhejiang University of Finance \& Economics, Hangzhou 310018, China \\ ${ }^{2}$ China Academy of Financial Research, Zhejiang University of Finance \& Economics, Hangzhou 310018, China \\ Correspondence should be addressed to Rongda Chen; rongdachen@163.com
}

Received 14 April 2016; Accepted 14 July 2016

Academic Editor: Xiaodong Lin

Copyright (c) 2016 Congcong Wang et al. This is an open access article distributed under the Creative Commons Attribution License, which permits unrestricted use, distribution, and reproduction in any medium, provided the original work is properly cited.

This article develops a model to investigate the entry strategies of private investors to the elderly care service market, with the purpose of explaining the reasons behind dilemma of low signing rate plaguing China's Public-Private Partnership projects. We focus on the competition between two private investors with or without mothballing options under price uncertainty. After the derivation of equilibria of entry strategies, we employ numerical examples to analyze the dependencies of entry thresholds on market parameters, cost parameters, subsidy, and possession of mothballing option. Conclusions are drawn and some policy implications are given with the intention to alleviate the problem of low signing rate.

\section{Introduction}

In recent years, the looming challenges of China's aging population draw more and more attentions. According to the disclosed data of National Bureau of Statistics of People's Republic of China, senior citizens (citizens over 60 years old) are expected to take up more than $30 \%$ of the total population in 2050, compared with only $18 \%$ in 2015 . Since 2014, the State Council of China has issued a series of policies to promote the Public-Private Partnerships (PPP) projects aiming to address the imminent challenges of aging population, motivating private investors to support the infrastructure, facilities, and human resources for elderly care services. More than $16 \%$ of all the PPP projects promoted by State Council are directly related to elderly care facilities. However, the private investors seem more conservative than expected. The signing rate of these PPP projects has remained at low level since the beginning. In April, 2015, National Development and Reform Commission (NDRC) estimated the signing rate to be between $10 \%$ and $20 \%$. With the implementation of simulation packages, polices including reduced financing costs, tax abatement, and government subsidies, the signing rate rose slowly to $31.5 \%$.
There are several reasons behind the low signing rate, and one of them is the market uncertainty. When private investors consider the participation of PPP projects, they face opportunities of irreversible investments. Just as the purchaser of the call option in financial derivative market, the potential private investor of PPP project holds a real option. The exercise of the real option, or signing of the PPP contract, depends on the prevailing market price (e.g., for elderly care service), as well as market volatility.

Competition is another important reason. Most contracts of elderly care PPP projects promoted do not contain clauses of exclusive licenses. The leader who provides elderly care service in a local community market cannot prevent the entry of follower and therefore has to consider the probability with which the monopoly market turns to a duopoly one and the resulting profit reduction.

Because of the aforementioned reasons, we use the framework of real option games to analyze the dilemma of low signing rate of PPP projects with the background of elder care industry. Smets first introduced game theory to real option analysis [1]. Based on Smets' work, Grenadier considered market uncertainty and used option games approach to analyze seemingly irrational real estate development cascades 
[2]. Huisman and Kort later considered an investment timing problem in a duopoly market [3]. Based on the assumption of symmetric duopoly, Grenadier developed Cournot Nash equilibrium option exercise strategies [4]. Huang and $\mathrm{Wu}$ further developed the duopoly option games to incorporate two sources of uncertainties, namely, market uncertainty and emergencies [5]. Qiu and Yu expanded the option games of only two firms to games in oligopoly setting [6]. Folta and O'Brien analyzed the tension between the option to defer and the option to grow and recognized the nonmonotonic effect [7]. Pawlina and Kort analyzed the impact of cost asymmetry on the optimal real option exercise strategies in duopoly setting [8]. Smit and Trigeorgis provided a valuation method to assess whether investors overpaid for infrastructure assets or a premium for the strategic growth option value was justified due to their operating flexibility [9]. Suttinon et al. proposed using option games to evaluate trade-offs between flexibility and strategic commitment in industrial water infrastructure projects [10]. Martzoukosa and Zachariasb demonstrated optimal exercise conditions for the real option to make costly strategic preinvestment $\mathrm{R} \& \mathrm{D}$ decisions in the presence of spillover effects with analytic tractability [11].

Among various types of real options, mothballing options have been discussed by many scholars recently. Mothballing option allows its holder to suspend operation if the market conditions are unfavorable. Takashima et al. analyzed the optimal strategies of two firms, with asymmetries in fixed cost, variable cost, and possession of mothballing options, to enter the electricity market under competition and uncertain price [12]. Zhang et al. expanded the model by incorporating the parameter of government subsidy [13]. Gao et al. developed a valuation model for investment of low-carbon power plant with mothballing options to calculate the investment threshold and its sensitivity to various market parameters [14]. Lv and Shao presented an asymmetric option game in an oligopoly market and derived investment thresholds for firms in the market [15].

The contribution of the paper is twofold. First, although there are many studies conducted using option game approach to analyze the competitions in several industries, elder care industry is not among them. We therefore use the real options approach and game theory to consider both uncertainty and competition in elderly care industry, which is particularly concerned by China's central government because of the looming challenge of the vast aging population. Second, among all the real options, such as options to expand, to contract, and to abandon, mothballing option is largely ignored in spite of its great potential. We focus our study on the mothballing option adopted by private elderly care facilities and analyze the effects of mothballing option on the entry thresholds of private investors in the elderly care industry.

We consider two symmetric potential private investors of PPP projects who compete with each other to enter elderly care service market. Neither of the two investors is in possession of mothballing options in the first case, while both of them have mothballing options in the second case. The dependencies of market entry thresholds on market parameters, cost parameters, subsidy, and possession of mothballing option are then analyzed.
We found that the entry thresholds for the private investors of PPP projects in elderly care industry decrease with the increase of expected growth rate and government subsidy and increase with the increase of volatility, discount rate, fixed cost, and variable cost. By comparing the dependencies of thresholds on different parameters, we found that volatility had more significant effect on thresholds than expected growth rate and that variable cost had more significant effect than fixed cost. Based on the results, we propose that the government should allow the inclusion of mothballing option in PPP contracts, reduce financing costs, and subsidize the facilities for their variable cost instead of fixed cost in elderly care PPP projects to increase the signing rate.

Our paper is organized as follows. Section 2 introduces the model and basic settings. In Section 3, we derive the entry thresholds and the optimal strategies of investors. In Section 4, we use numerical examples with realistic parameter specifications to demonstrate our results and policy implications. Section 5 concludes.

\section{Model}

We consider two potential private investors of PPP projects, labeled as 1 and 2. Index 1 represents an arbitrary investor, and index 2 represents the other. We assume that they are willing to enter the elderly care market if the entry thresholds are reached, and these investors' decisions affect each other.

The profit function of investor $i$ at time $t(>0)$ satisfies

$$
\pi_{i}\left(Q_{t}, X_{t}\right)=D\left(Q_{t}\right)\left(X_{t}-C_{i}\right), \quad i=1,2,
$$

where $D\left(Q_{t}\right)$ is the demand parameter for investors given $Q_{t}$, the number of investors that have entered the elderly care market. $X_{t}$ is the price per unit of elderly care service, and $C_{i}$ is the variable cost per unit. If investor $i$ has mothballing option, the profit function is given by

$$
\pi_{i}\left(Q_{t}, X_{t}\right)=D\left(Q_{t}\right) \max \left\{X_{t}-C_{i}, 0\right\}, \quad i=1,2 .
$$

Furthermore, we assume the price at time $t$ follows a geometric Brownian motion

$$
d X_{t}=\mu X_{t} d t+\sigma X_{t} d W_{t} \quad X_{0}=x
$$

where $\mu$ denotes the instantaneous expected growth rate of $X_{t}, \sigma(>0)$ denotes the instantaneous volatility of $X_{t}$, and $W_{t}$ denotes a standard Wiener process.

Then, the value function of investor $i$ is given by

$$
\begin{array}{r}
V_{i}(x)=\sup _{\tau_{i} \in T} E\left[1_{\left\{\tau_{i}<\tau_{j}\right\}} \int_{\tau_{i} \wedge \tau_{j}}^{\tau_{i} \vee \tau_{j}} e^{-r t} \pi_{i}\left(1, X_{t}\right) d t\right. \\
\left.+\int_{\tau_{i} \vee \tau_{j}}^{\infty} e^{-r t} \pi_{i}\left(2, X_{t}\right) d t-e^{-r \tau_{i}} I_{i}+e^{-r \tau_{i}} S_{i}\right],
\end{array}
$$

where $\tau_{i}$ denotes the stopping time for investor $i$ to enter the market, $T$ denotes the collection of admissible stopping times, $r(>\mu)$ denotes a discount rate, $I_{i}$ denotes the fixed investment cost for the investor $i$, and $S_{i}$ denotes the government subsidy for investor $i$. 
We assume that the private investors are price-takers, and the entries of these investors have no effect on prices for elderly care services. These are reasonable assumptions, because the prices for care services for senior citizens in China are regulated by government and fluctuate randomly due to expansion of the market, changing policies and other sources of uncertainty. However, the two elderly care facilities constructed by private investors in our models can be assumed to have impact on the sales volume of each other, since they are the competitors who provide the services of the same quality in the same local community. There are three patterns of entry. If $\tau_{i}<\tau_{j}$, investor $i$ enters the market first at time $\tau_{i}$ and earns a higher profit (temporary monopoly profit) until investor $j$ enters the market at $\tau_{j}$. In this case, investor $i$ is called the leader, and $V_{i}(x):=L_{i}(x)$. If $\tau_{i}>\tau_{j}$, investor $j$ (leader) enters the market first at $\tau_{j}$, and investor $i$ waits to enter the market and earns no profit until $\tau_{i}$. In this case, investor $i$ is called the follower, and $V_{i}(x):=F_{i}(x)$. If $\tau_{i}=\tau_{j}$, both investors earn lower profit because they enter the market simultaneously and share the market from time $\tau_{i}$. This case is called simultaneous investment, and in this case $V_{i}(x):=$ $M_{i}(x)$. We assume that each investor strives to maximize their investment value (present value), and therefore we maximize the value function equation (4) in the next section at the moment the leader has entered, $\tau_{i} \wedge \tau_{j}$, after Grenadier [2] and Takashima et al. [12].

\section{Equilibria}

3.1. Case 1: Two Investors without Mothballing Option. In this case, the two investors are identical and willing to enter the elderly care market. First, we obtain the value function of simultaneous investment

$$
M_{1}(x)=E\left[\int_{0}^{\infty} D(2) e^{-r t}\left(X_{t}-C\right) d t-I+S\right] .
$$

Since neither of the investors is in possession of mothballing option, we have

$$
M_{1}(x)=D(2)\left(\frac{x}{\delta}-\frac{C}{r}\right)-I+S,
$$

where $\delta=r-\mu$.

We then consider the follower's value. Since the leader has already entered the market, the value function of the follower is obtained by

$$
\begin{aligned}
& F_{1}(x)=\sup _{\tau_{1} \in T} E\left[\int_{\tau_{1}}^{\infty} D(2) e^{-r t}\left(X_{t}-C\right) d t-e^{-r \tau_{1}} I\right. \\
& \left.+e^{-r \tau_{1}} S\right],
\end{aligned}
$$

where $\tau_{1}$ is the stopping time for the follower to enter and $T$ is the collection of admissible stopping times. We assume that the constant threshold of the follower $Y_{1}$ is given; then $\tau_{1}$ satisfies

$$
\tau_{1}=\inf \left\{t>0: X_{t} \geq Y_{1}\right\}
$$

According to the Bellman equation and Ito's lemma, we calculate the value function of the follower by the following ordinary differential equation:

$$
\frac{1}{2} \sigma^{2} x^{2} \frac{d^{2} F_{1}(x)}{d x^{2}}+\mu x \frac{d F_{1}(x)}{d x}-r F_{1}(x)=0
$$

with boundary conditions

$$
\begin{aligned}
F_{1}(0) & =0, \\
F_{1}\left(Y_{1}\right) & =M_{1}\left(Y_{1}\right), \\
\left.\frac{d F_{1}(x)}{d x}\right|_{x=Y_{1}} & =\left.\frac{d M_{1}(x)}{d x}\right|_{x=Y_{1}} .
\end{aligned}
$$

Among the three boundary conditions, the second condition is called the value-matching condition and the third is called the smooth-pasting condition. From (9) and (10), we have

$$
\begin{aligned}
& F_{1}(x) \\
& \quad= \begin{cases}{\left[D(2)\left(\frac{Y_{1}}{\delta}-\frac{C}{r}\right)-I+S\right]\left(\frac{x}{Y_{1}}\right)^{\beta_{1}}} & \text { if } x<Y_{1}, \\
D(2)\left(\frac{x}{\delta}-\frac{C}{r}\right)-I+S & \text { if } x \geq Y_{1},\end{cases}
\end{aligned}
$$

and the optimal entry price for the follower is

$$
Y_{1}=\frac{\beta_{1}}{\beta_{1}-1} \delta\left(\frac{I-S}{D(2)}+\frac{C}{r}\right)
$$

where $\beta_{1}$ is the positive root of the following quadratic equation:

$$
\frac{1}{2} \delta^{2} \beta(\beta-1)+\mu \beta-r=0
$$

We now consider the leader's side. Suppose that the follower chooses the optimal policy; we obtain the value function of the leader as follows:

$$
\begin{gathered}
L_{1}(x)=E\left[\int_{0}^{\tau_{1}} D(1) e^{-r t}\left(X_{t}-C\right) d t\right. \\
\left.+\int_{\tau_{1}}^{\infty} D(2) e^{-r t}\left(X_{t}-C\right) d t-I+S\right] .
\end{gathered}
$$

Similarly, according to the Bellman equation and Ito's lemma, the value function of the leader satisfies the following ordinary differential equation:

$$
\frac{1}{2} \sigma^{2} x^{2} \frac{d^{2} L_{1}(x)}{d x^{2}}+\mu x \frac{d L_{1}(x)}{d x}-r L_{1}(x)=0,
$$

with boundary conditions

$$
\begin{aligned}
L_{1}(0) & =0, \\
L_{1}\left(Y_{1}\right) & =F_{1}\left(Y_{1}\right) .
\end{aligned}
$$


Here, the smooth-pasting condition is not necessary, because (14) is not a maximum problem. From (14) and (15), we have

$$
L_{1}(x)= \begin{cases}\frac{\beta_{1}}{\beta_{1}-1} \frac{D(2)-D(1)}{D(2)}\left[I-S+\frac{D(2) C}{\beta_{1} r}\right]\left(\frac{x}{Y_{1}}\right)^{\beta_{1}}+D(1)\left(\frac{x}{\delta}-\frac{C}{r}\right)-I+S & \text { if } x<Y_{1} \\ D(2)\left(\frac{x}{\delta}-\frac{C}{r}\right)-I+S & \text { if } x \geq Y_{1} .\end{cases}
$$

Proposition 1. There exists a unique value for $x$, labeled as $Z_{1}$, such that

$$
L_{1}\left(Z_{1}\right)=F_{1}\left(Z_{1}\right), \quad 0<Z_{1}<Y_{1} \text {. }
$$

The stopping time is defined as

$$
\lambda_{1}=\inf \left\{t>0: X_{t} \geq Z_{1}\right\} .
$$

$Z_{1}$ does not have the analytical solution and therefore has to be numerically determined by the following equation:

$$
\begin{aligned}
& \frac{\beta_{1}}{\beta_{1}-1} \frac{D(2)-D(1)}{D(2)}\left[I-S+\frac{D(2) C}{\beta_{1} r}\right]\left(\frac{Z_{1}}{Y_{1}}\right)^{\beta_{1}} \\
& +D(1)\left(\frac{Z_{1}}{\delta}-\frac{C}{r}\right)-I+S \\
& =\left[D(2)\left(\frac{Y_{1}}{\delta}-\frac{C}{r}\right)-I+S\right]\left(\frac{Z_{1}}{Y_{1}}\right)^{\beta_{1}} .
\end{aligned}
$$

We use the strategy space and equilibrium concept defined by Huisman and Kort [3] due to Proposition 1 and obtain the equilibrium in this case.

Proposition 2. Depending on the value of $x$, there exist three types of equilibria:

(1) If $x \in\left(0, Z_{1}\right)$, there are two possible scenarios. In the first one, investor 1 is the leader and enters the elderly care market at time $\lambda_{1}$, and investor 2 is the follower and enters at time $\tau_{1}$ with probability $1 / 2$. The second is the symmetric counterpart, and the probability that both investors enter simultaneously is zero.

(2) If $x \in\left(Z_{1}, Y_{1}\right)$, there are three possible scenarios. In the first, investor 1 is the leader and enters the market at time 0 , and investor 2 is the follower and enters at time $\tau_{1}$ with probability $\left(F_{1}(x)-M_{1}(x)\right) /\left(L_{1}(x)+F_{1}(x)-\right.$ $\left.2 M_{1}(x)\right)$. The second is the symmetric counterpart. In the third, both investors enter simultaneously at time 0 with probability $\left(L_{1}(x)-F_{1}(x)\right) /\left(L_{1}(x)+F_{1}(x)-\right.$ $\left.2 M_{1}(x)\right)$.

(3) If $x \in\left(Y_{1}, \infty\right)$, then both investors enter at time 0 with probability 1 .

The proof is presented by Huisman and Kort [3]. Proposition 2 states that there is no simultaneous investment if the game starts with low price for elderly care service.

3.2. Case 2: Two Investors with Mothballing Options. In Case 2 , the two investors are identical and willing to enter the elderly care market as in Case 1 . The difference is that the elderly care facilities can now temporarily suspend their operation if the price for care service is unfavorable (less than the variable cost).

We first obtain the value function of simultaneous investment

$$
\begin{aligned}
& M_{2}(x) \\
& \quad=E\left[\int_{0}^{\infty} D(2) e^{-r t} \max \left\{X_{t}-C, 0\right\} d t-I+S\right] .
\end{aligned}
$$

According to the Bellman equation and Ito's lemma, we calculate the value function of simultaneous investment by the following ordinary differential equation:

$$
\begin{gathered}
\frac{1}{2} \sigma^{2} x^{2} \frac{d^{2} M_{2}(x)}{d x^{2}}+\mu x \frac{d M_{2}(x)}{d x}-r M_{2}(x) \\
+D(2) \max \{x-C, 0\}=0
\end{gathered}
$$

with the value-matching condition and the smoothing-pasting condition at $x=C$ similar to Case 1 ; we have

$$
M_{2}(x)= \begin{cases}\frac{D(2) C}{\beta_{1}-\beta_{2}}\left(\frac{1-\beta_{2}}{\delta}+\frac{\beta_{2}}{r}\right)\left(\frac{x}{C}\right)^{\beta_{1}}-I+S & \text { if } x<C, \\ \frac{D(2) C}{\beta_{1}-\beta_{2}}\left(\frac{1-\beta_{1}}{\delta}+\frac{\beta_{1}}{r}\right)\left(\frac{x}{C}\right)^{\beta_{2}}+D(2)\left(\frac{x}{\delta}-\frac{C}{r}\right)-I+S & \text { if } x \geq C\end{cases}
$$

where $\beta_{2}$ is the negative root of (13). 
We then consider the value function of the follower. Since the leader has already entered the market, we have

$$
\begin{aligned}
& F_{2}(x)=\sup _{\tau_{2} \in T} E\left[\int_{\tau_{2}}^{\infty} D(2) e^{-r t} \max \left\{X_{t}-C, 0\right\} d t\right. \\
& \left.-e^{-r \tau_{2}} I+e^{-r \tau_{2}} S\right]
\end{aligned}
$$

where $\tau_{2}$ denotes the stopping time for the follower to enter. Assuming that the threshold of the follower $Y_{2}$ is given, $\tau_{2}$ takes the form of

$$
\tau_{2}=\inf \left\{t>0: X_{t} \geq Y_{2}\right\}
$$

As in Case 1, we have

$$
F_{2}(x)= \begin{cases}{\left[\frac{D(2) C}{\beta_{1}-\beta_{2}}\left(\frac{1-\beta_{1}}{\delta}+\frac{\beta_{1}}{r}\right)\left(\frac{Y_{2}}{C}\right)^{\beta_{2}}+D(2)\left(\frac{Y_{2}}{\delta}-\frac{C}{r}\right)-I+S\right]\left(\frac{x}{Y_{2}}\right)^{\beta_{1}}} & \text { if } x<Y_{2}, \\ \frac{D(2) C}{\beta_{1}-\beta_{2}}\left(\frac{1-\beta_{1}}{\delta}+\frac{\beta_{1}}{r}\right)\left(\frac{x}{C}\right)^{\beta_{2}}+D(2)\left(\frac{x}{\delta}-\frac{C}{r}\right)-I+S & \text { if } x \geq Y_{2} .\end{cases}
$$

The optimal threshold $Y_{2}$ does not have analytical solution. From the smooth-pasting condition at $x=Y_{2}$, it can be numerically determined by the following equation:

$$
\begin{aligned}
& {\left[\frac{D(2) C}{\beta_{1}-\beta_{2}}\left(\frac{1-\beta_{1}}{\delta}+\frac{\beta_{1}}{r}\right)\left(\frac{Y_{2}}{C}\right)^{\beta_{2}}+D(2)\left(\frac{Y_{2}}{\delta}-\frac{C}{r}\right)\right.} \\
& -I+S] \beta_{1} Y_{2}^{-1}=\frac{D(2)}{\beta_{1}-\beta_{2}}\left(\frac{1-\beta_{1}}{\delta}+\frac{\beta_{1}}{r}\right) \\
& \cdot \beta_{2}\left(\frac{Y_{2}}{C}\right)^{\beta_{2}-1}+\frac{D(2)}{\delta} .
\end{aligned}
$$

By solving (27), we have the solution of $Y_{2}$.
Assuming that the follower chooses the optimal strategy, the value function of the leader is given by

$$
\begin{aligned}
& L_{2}(x)=E\left[\int_{0}^{\tau_{2}} D(1) e^{-r t} \max \left\{X_{t}-C, 0\right\} d t\right. \\
& \left.+\int_{\tau_{2}}^{\infty} D(2) e^{-r t} \max \left\{X_{t}-C, 0\right\} d t-I+S\right] .
\end{aligned}
$$

From Case 1, we obtain the value function of the leader

$$
L_{2}(x)= \begin{cases}\frac{D(1) C}{\beta_{1}-\beta_{2}}\left(\frac{1-\beta_{2}}{\delta}+\frac{\beta_{2}}{r}\right)\left(\frac{x}{C}\right)^{\beta_{1}}-I+S+B_{2} x^{\beta_{1}} & \text { if } x<C, \\ \frac{D(1) C}{\beta_{1}-\beta_{2}}\left(\frac{1-\beta_{1}}{\delta}+\frac{\beta_{1}}{r}\right)\left(\frac{x}{C}\right)^{\beta_{2}}+D(1)\left(\frac{x}{\delta}-\frac{C}{r}\right)-I+S+B_{2} x^{\beta_{1}} & \text { if } C \leq x<Y_{2}, \\ \frac{D(2) C}{\beta_{1}-\beta_{2}}\left(\frac{1-\beta_{1}}{\delta}+\frac{\beta_{1}}{r}\right)\left(\frac{x}{C}\right)^{\beta_{2}}+D(2)\left(\frac{x}{\delta}-\frac{C}{r}\right)-I+S & \text { if } x \geq Y_{2},\end{cases}
$$

where

$$
\begin{aligned}
& B_{2}=[D(2)-D(1)] \\
& \cdot {\left[\frac{C}{\beta_{1}-\beta_{2}}\left(\frac{1-\beta_{1}}{\delta}+\frac{\beta_{1}}{r}\right)\left(\frac{Y_{2}}{C}\right)^{\beta_{2}}+\frac{Y_{2}}{\delta}-\frac{C}{r}\right] } \\
& \cdot Y_{2}^{-\beta_{1}} .
\end{aligned}
$$

Proposition 3. There exists a unique value for $x$, labeled as $Z_{2}$, such that

$$
L_{2}\left(Z_{2}\right)=F_{2}\left(Z_{2}\right), \quad C<Z_{2}<Y_{2} \text {. }
$$

The stopping time is defined as

$$
\lambda_{2}=\inf \left\{t>0: X_{t} \geq Z_{2}\right\} .
$$

$Z_{2}$ has to be numerically determined by the following equation:

$$
\begin{aligned}
& {\left[\frac{D(2) C}{\beta_{1}-\beta_{2}}\left(\frac{1-\beta_{1}}{\delta}+\frac{\beta_{1}}{r}\right)\left(\frac{Y_{2}}{C}\right)^{\beta_{2}}+D(2)\left(\frac{Y_{2}}{\delta}-\frac{C}{r}\right)\right.} \\
& -I+S]\left(\frac{Z_{2}}{Y_{2}}\right)^{\beta_{1}}=\frac{D(1) C}{\beta_{1}-\beta_{2}}\left(\frac{1-\beta_{1}}{\delta}+\frac{\beta_{1}}{r}\right) \\
& \cdot\left(\frac{Z_{2}}{C}\right)^{\beta_{2}}+D(1)\left(\frac{Z_{2}}{\delta}-\frac{C}{r}\right)-I+S+[D(2) \\
& -D(1)]\left[\frac{C}{\beta_{1}-\beta_{2}}\left(\frac{1-\beta_{1}}{\delta}+\frac{\beta_{1}}{r}\right)\left(\frac{Y_{2}}{C}\right)^{\beta_{2}}+\frac{Y_{2}}{\delta}\right. \\
& \left.-\frac{C}{r}\right]\left(\frac{Z_{2}}{Y_{2}}\right)^{\beta_{1}} .
\end{aligned}
$$


TABLE 1: Parameter specifications for the elderly care service market.

\begin{tabular}{lccc}
\hline Parameter & Variable & Value & Unit \\
\hline Discount rate & $r$ & 0.05 & /year \\
Expected growth rate & $\mu$ & 0.04 & /year \\
Volatility & $\sigma$ & 0.20 & /year \\
Demand (1) & $D(1)$ & 4.00 & Beds \\
Demand (2) & $D(2)$ & 2.50 & Beds \\
Variable cost & $C$ & 2.00 & $10^{4} \mathrm{RMB}$ Yuan/year \\
Fixed cost & $I$ & 100.00 & $10^{4} \mathrm{RMB}$ Yuan/year \\
Government subsidy & $S$ & 7.00 & $10^{6} \mathrm{RMB}$ Yuan/year \\
\hline
\end{tabular}

Again, we use the strategy space and equilibrium concept defined by Huisman and Kort [3] based on Proposition 3.

Proposition 4. Depending on the value of $x$, there exist three types of equilibria:

(1) If $x \in\left(0, Z_{2}\right)$, there are two possible scenarios. In the first one, investor 1 is the leader and enters the elder care market at time $\lambda_{2}$, and investor 2 is the follower and enters at time $\tau_{2}$ with probability $1 / 2$. The second is the symmetric counterpart, and the probability that both investors enter simultaneously is zero.

(2) If $x \in\left(Z_{2}, Y_{2}\right)$, there are three possible scenarios. In the first, investor 1 is the leader and enters the market at time 0 , and investor 2 is the follower and enters at time $\tau_{2}$ with probability $\left(F_{2}(x)-M_{2}(x)\right) /\left(L_{2}(x)+F_{2}(x)-\right.$ $\left.2 M_{2}(x)\right)$. The second is the symmetric counterpart. In the third, both investors enter simultaneously at time 0 with probability $\left(L_{2}(x)-F_{2}(x)\right) /\left(L_{2}(x)+F_{2}(x)-\right.$ $2 M_{2}(x)$ ).

(3) If $x \in\left(Y_{2}, \infty\right)$, then both investors enter at time 0 with probability 1 .

The proof is the same as Huisman and Kort [3].

\section{Numerical Examples}

In Sections 2 and 3, we developed models which enable us to analyze the entry strategies of potential private investors to the elderly care service market and then derived equilibria in two duopoly market cases. In the first case, neither of the two potential investors is in possession of mothballing option, while in the second case, both of them have the mothballing options.

In this section, we use specific values for parameters, which have realistic meanings, to calculate the entry thresholds of leader and follower in a local elderly care service market.

4.1. Parameter Specifications. Table 1 shows the parameter specifications for our models. The discount rate is set to 0.05 , the prevailing interest rate for government supported projects in China. The growth rate of Chinese senior citizens is predicted to be $1.3 \%$ per year, which is calculated based on the published data of National Bureau of Statistics of People's
TABLE 2: Optimal entry strategies for leader and follower to the elderly care service market.

\begin{tabular}{lc}
\hline Threshold & Value \\
\hline$Y$ without mothballing option & 5.6478 \\
$Z$ without mothballing option & 3.8524 \\
$Y$ with mothballing option & 5.5453 \\
$Z$ with mothballing option & 0.7503 \\
\hline
\end{tabular}

Republic of China in April, 2015, and the elderly care service market is expected to grow at the rate of $4.1 \%$. The expected growth rate in our model is therefore set to 0.04 . We estimate the volatility of the elderly care service market by calculating the average standard deviation of annual earnings per share of listed companies which provide care services for senior citizens in China, and the result is 0.2 .

We conducted survey in elderly care service markets in the three major cities in Zhejiang Province: Hangzhou, Ningbo, and Wenzhou. The survey results show that the average capacity of elderly care facilities is around 400 beds, the fixed cost is about RMB 250000 Yuan per bed (or RMB 100 million Yuan for a facility with 400 beds), and the variable cost for one bed is averagely RMB 1650 Yuan per month (or about RMB 20000 Yuan annually). The present value of government subsidy to an elderly care facility with 400 beds is roughly RMB 7 million Yuan. According to our survey, we set $D(1)$ to 4.0 (400 beds), $D(2)$ to 2.5 , fixed cost to 100 (RMB 100 million Yuan for a facility with 400 beds), variable cost to 2.0 (RMB 20000 Yuan annually), and subsidy to 7 (RMB 7 million Yuan).

4.2. Entry Thresholds. Table 2 shows the optimal entry strategies for leader and follower to the elderly care service market. In the first case, neither of the two investors has mothballing option. The entry threshold of leader in the first case is 3.8524, suggesting that leader will enter the market if the market price is above RMB 38524 per bed annually, or equivalently around RMB 3200 per bed monthly. The entry threshold of follower in this case is 5.6478. In the second case, both investors possess the mothballing option. The entry threshold of leader now is only 0.7503 , which is significantly lower than that in the first case, and the threshold of follower is 5.5453, which is lower than that in the first case too.

The results in Table 2 suggest that both leader and follower will enter the market sooner if mothballing options are introduced into the industry. Because the entry threshold of leader with mothballing option is significantly lower than that without the option, by holding mothballing options, private investors tend to enter the market significantly earlier, if the community has no elderly care facility and the investors can compete to be the leader in this case. The mothballing option facilitates the entry of private investors even if there is already an elderly care facility established in the local community and new investor will be the absolute follower, since the entry threshold of follower with mothballing option is lower than that without the option.

Our model therefore implies that the signing rate of PPP projects of elderly care facilities will be significantly higher, 


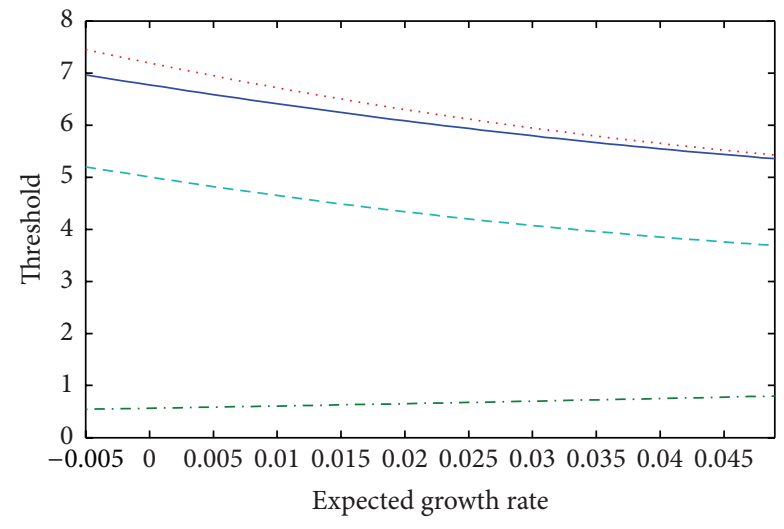

— $Y$ with mothballing option

-.. $Z$ with mothballing option

…. $Y$ without mothballing option

- - $Z$ without mothballing option

Figure 1: The entry thresholds of leader and follower on the expected growth rate $\mu$ with model parameters: $D(1)=4.00, D(2)=$ $2.50, r=0.05, \sigma=0.20, C=2.0, I=100$, and $S=7$.

if government allows private investors providing elderly care service to suspend their operation when the market price for care service is unfavorable (lower than variable cost). Meanwhile, the service can be provided by state owned facilities until market conditions become acceptable again for private investors.

4.3. Market Parameters. From the presented models and derived entry thresholds, we observe the fact that mothballing options, inflation rate, market volatility, discount rate, fixed cost, and government subsidy all have impacts on private investor's entry strategy. We numerically simulate the effects of aforementioned parameters on entry thresholds. All numerical results are implemented in Matlab. Figures 1-6 illustrate the thresholds of leader and follower as functions of the market, cost, and subsidy parameters.

Figure 1 shows that the entry thresholds of private investors of elderly care facilities decline with the increase of $\mu$, which means that the investors are more willing to enter the market knowing that the market is expanding quickly. Figure 1 also suggests that the slopes of threshold curves of followers are greater than those of the leaders, indicating greater effect of $\mu$ on followers. Comparing threshold curves of investors with and without mothballing options, we notice that the entry thresholds of leader and follower with mothballing options are less sensitive to the expected growth rate, $\mu$.

Figure 2 implies that investors are more reluctant to enter the market as uncertainty of the market increases. The slopes of threshold curves of the followers are larger than those of the leaders, suggesting that the effect of $\sigma$ on the follower side is stronger. Counterintuitively, entry threshold curve of the leader with mothballing option is not monotone. It increases along with the increase of market volatility at the beginning and then decreases when volatility is larger. The effect of $\sigma$ on the threshold of leader with mothballing option is twofold.

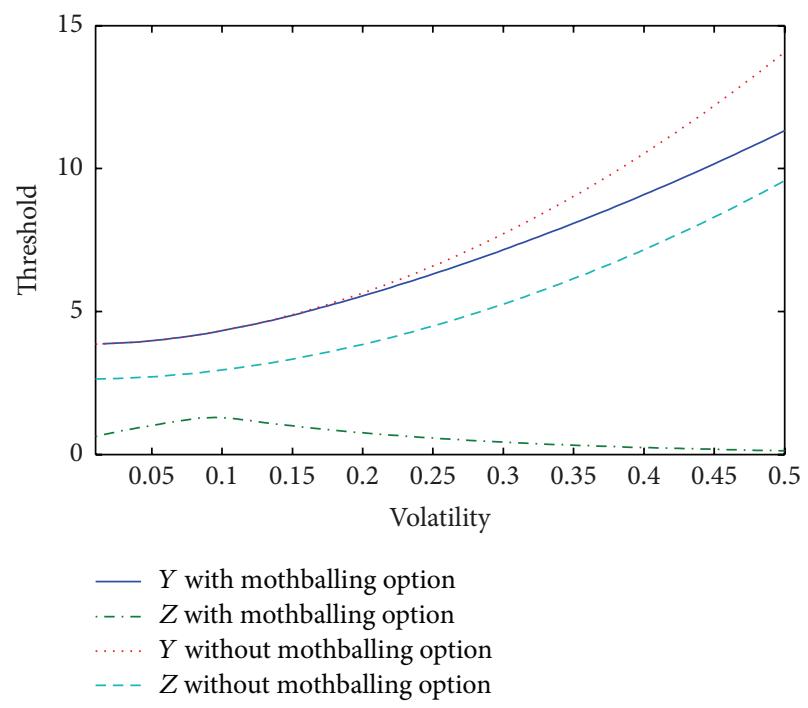

Figure 2: The entry thresholds of leader and follower on the volatility $\sigma$ with model parameters: $D(1)=4.00, D(2)=2.50, r=0.05$, $\mu=0.04, C=2.0, I=100$, and $S=7$.

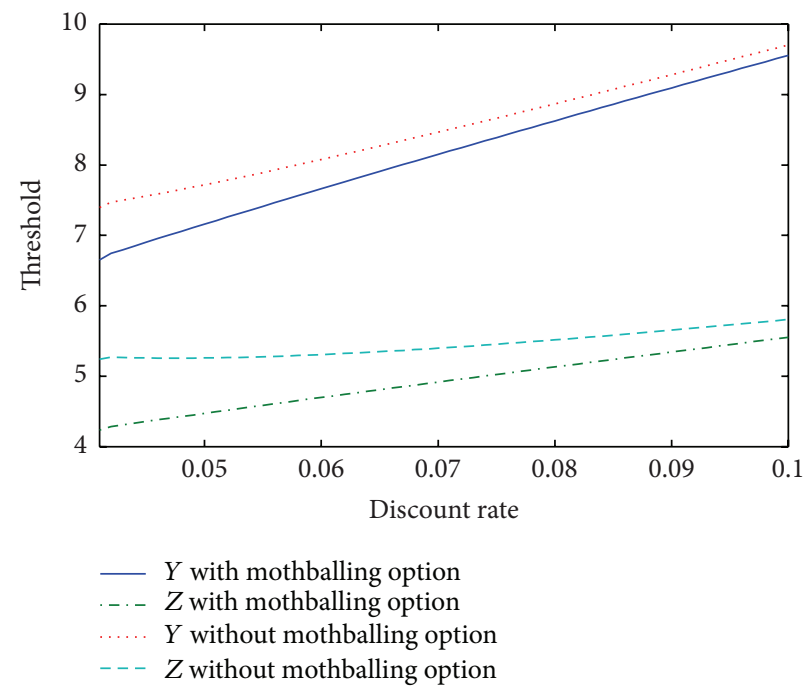

Figure 3: The entry thresholds of leader and follower on the discount rate $r$ with model parameters: $D(1)=4.00, D(2)=2.50, \mu=$ $0.04, \sigma=0.20, C=2.0, I=100$, and $S=7$.

On one hand, the leader with mothballing option is averse to market uncertainty (however, notice that the degree of uncertainty-averse of investor with mothballing option is less than that without mothballing option), and the value of real option of entry decision is large, which raises the threshold at the beginning. The investors, therefore, tend to postpone the entry. On the other hand, the effect of $\sigma$ on the follower is very strong, and the thresholds of followers rise sharply with the increase in $\sigma$, indicating an evident preemption effect. The competition hastens the entry of leader. Hence the threshold curve of leader with mothballing option demonstrates a nonmonotonous shape. 


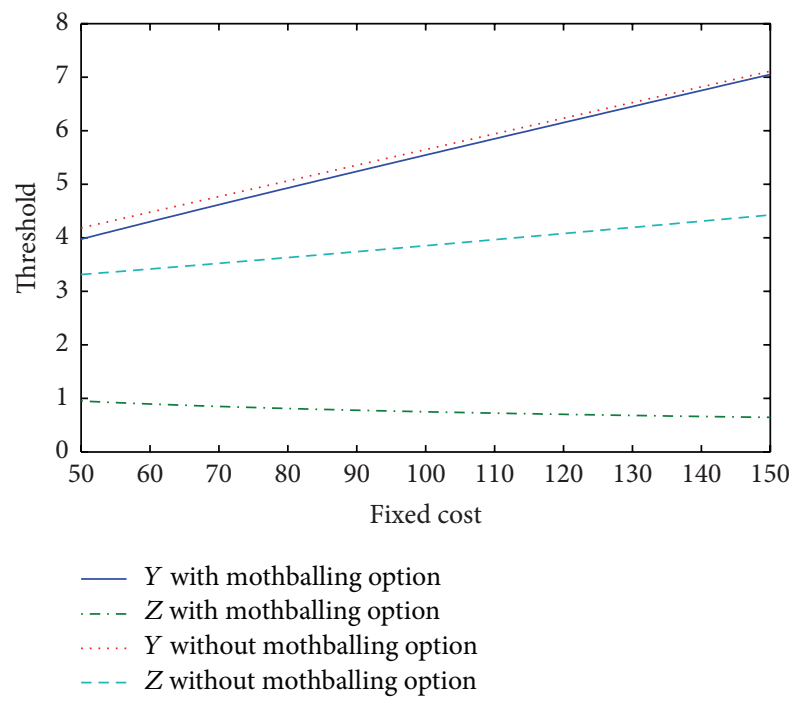

FIgURE 4: The entry thresholds of leader and follower on the fixed cost $I$ with model parameters: $D(1)=4.00, D(2)=2.50, r=0.05$, $\mu=0.04, \sigma=0.20, C=2.0$, and $S=7$.

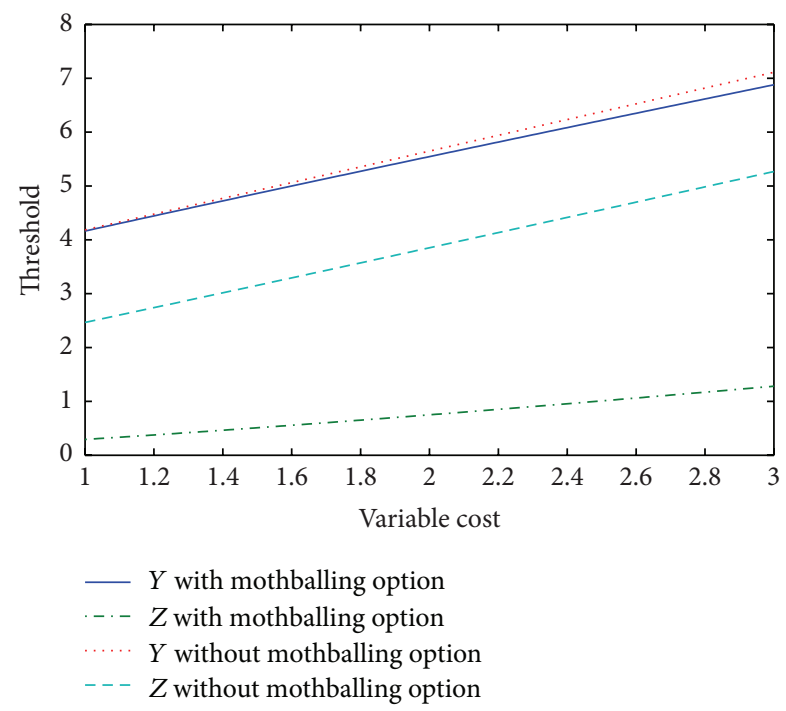

FIGURE 5: The entry thresholds of leader and follower on the variable cost $C$ with model parameters: $D(1)=4.00, D(2)=2.50, r=0.05$, $\mu=0.04, \sigma=0.20, I=100$, and $S=7$.

The entry thresholds of all investors increase as discount rate $r$ rises, as shown in Figure 3, indicating that private investors are less likely to enter the market when financing cost is higher. With other parameters remaining constant, the slopes of threshold curves of the followers are steeper than those of the leaders, and the threshold curves of both the leader and follower with mothballing options are steeper than those without the options. It therefore can be concluded that the effect of discount rate on follower is stronger than that on leader, and the effect of discount rate on investors with mothballing options is stronger than that on investors without the options.

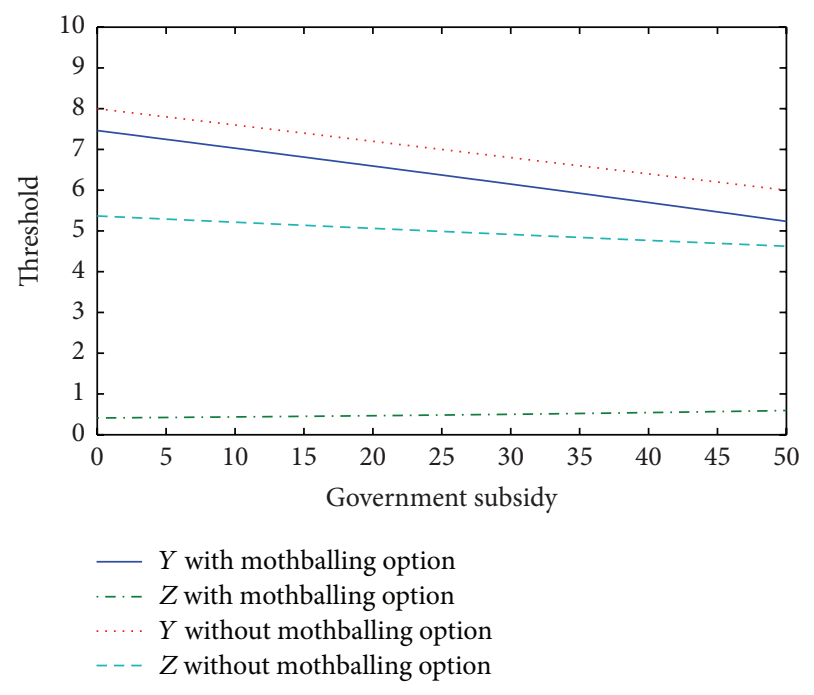

Figure 6: The entry thresholds of leader and follower on the government subsidy $S$ with model parameters: $D(1)=4.00, D(2)=$ $2.50, r=0.05, \mu=0.04, \sigma=0.20, C=2.0$, and $I=100$.

4.4. Cost Parameters. In Figure 4, with the increase of fixed cost, $I$, investors are less willing to enter the market as entry thresholds rise. Ceteris paribus, the threshold curves of followers are steeper than those of the leaders, which implies asymmetric effects of $I$ on leaders and followers: the effect of the variation of fixed cost on the followers is more significant than that on the leaders. As $I$ increases, although all investors are less willing to enter the market, the followers' thresholds with mothballing option rise most sharply. However, the leader's threshold with mothballing option shows a slow decrease, indicating the presence of preemption effect caused by competition.

Figure 5 illustrates that entry thresholds rise with the increase of variable cost, $C$. It shows that investors are more reluctant to enter the market when variable cost is higher. Specifically, the effect of variable cost on followers is greater than that on leaders, and the effect on the leaders and followers without mothballing options is greater than that on the investors with the options. However, different from the effect of the fixed cost, the leader's threshold with mothballing option rises because of the increase in variable cost, which implies that the willingness to enter the market of leader with mothballing option is more sensitive to variable cost than to fixed cost.

4.5. Subsidy Parameter. Figure 6 demonstrates that entry thresholds decline as government subsidy, $S$, increases. The figure also shows the fact that the effect of government subsidy on followers is greater than that on leaders, since the slopes of threshold curves of the followers are steeper than those of the leaders. Strikingly, the entry threshold of leader with mothballing option is almost constant, while thresholds of elderly care facility investors without mothballing option decrease significantly with the increase in subsidy. This finding suggests that government can cut the spending for subsidizing fixed cost of the elderly care facility simply by 


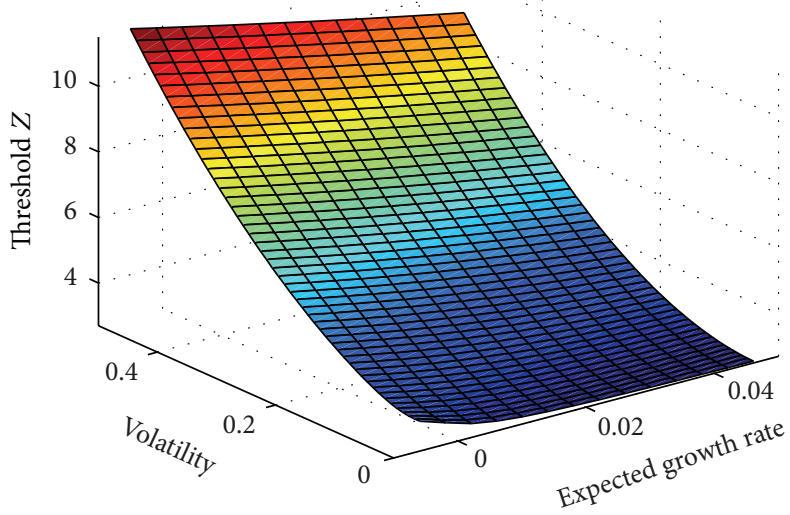

(a)

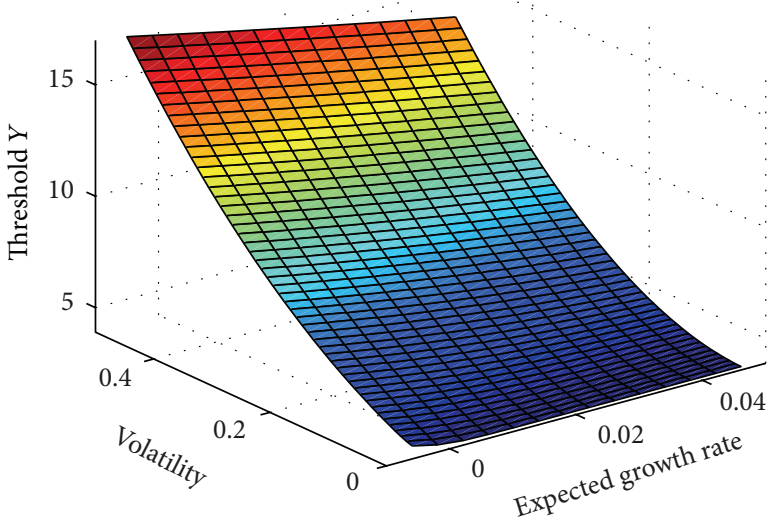

(c)

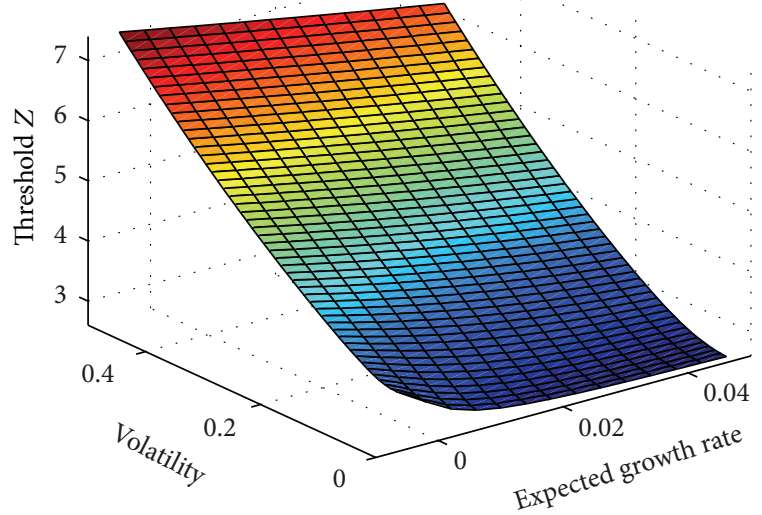

(b)

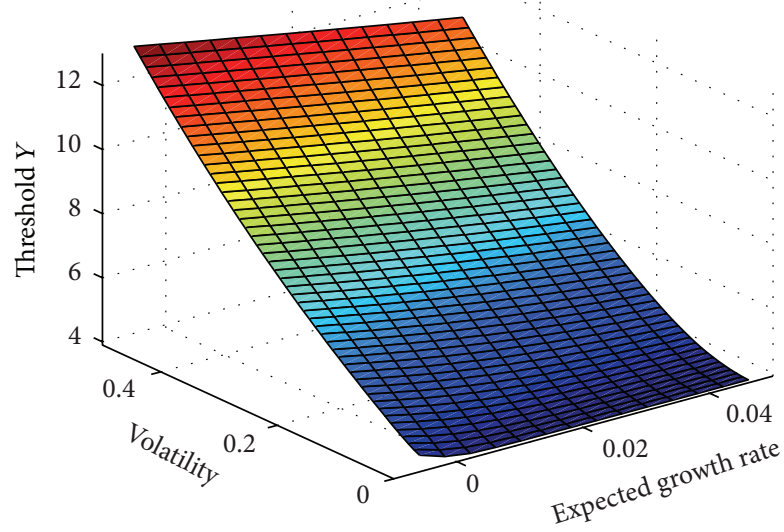

(d)

Figure 7: Dependencies of entry thresholds of leader (a) with and (b) without mothballing options on the market parameters with model specifications $D(1)=4.00, D(2)=2.50, r=0.05, C=2.00, I=100$, and $S=7$. Under the same model setup, dependencies of entry thresholds of follower (c) with and (d) without mothballing options on the market parameters are shown.

adding mothballing options to PPP project contracts without losing too much signing rate, since the threshold of leader with the option is inert to government subsidy.

4.6. Comparative Analysis. Figure 7 demonstrates the dependencies of thresholds of leader and follower on the market parameters: expected growth rate, $\mu$, and volatility, $\sigma$. Regardless of whether the investors of elderly care facilities own the mothballing options or not, the effect of market volatility on the threshold of the leader is significantly greater than that of expected growth rate. Under the premises that the leader has entered the elderly care service market, the threshold of the follower with mothballing option has similarly greater sensitivity to market volatility than to expected growth rate.

Figure 8 illustrates the dependencies of entry thresholds of leader and follower on the cost parameters: fixed cost, $I$, and variable cost, $C$. Regardless of whether the private investors of elderly care facilities own the mothballing options or not, the effect of the variable cost on entry thresholds is greater than that of the fixed cost, and the sensitivities of the investors with mothballing options to variable cost are greater than those without the options. For the followers, however, the difference between the effects of the variable cost and the fixed cost is less evident. From our numerical example, we find that the effect of fixed cost on threshold is not as much as variable cost, despite the fact that fixed cost represents the largest lump-sum cash outflow. Therefore, it is more efficient to subsidize private investors for their variable cost than for fixed cost in PPP projects of elderly care service.

Figure 9 shows that, regardless of whether the investors have the mothballing option or not, the effect of variable cost on entry thresholds of both leader and follower is greater than that of government lump-sum subsidy, $S$, and the effects of subsidy on the followers' threshold are more evident, compared with those on the leaders' threshold.

4.7. Policy Implications. The models and numerical examples we present here shed some light on the reasons behind current dilemma plaguing PPP projects of elderly care facilities in China and have several policy implications. According to our numerical examples, the entry threshold for leader without mothballing option is RMB 38524 Yuan annually, 


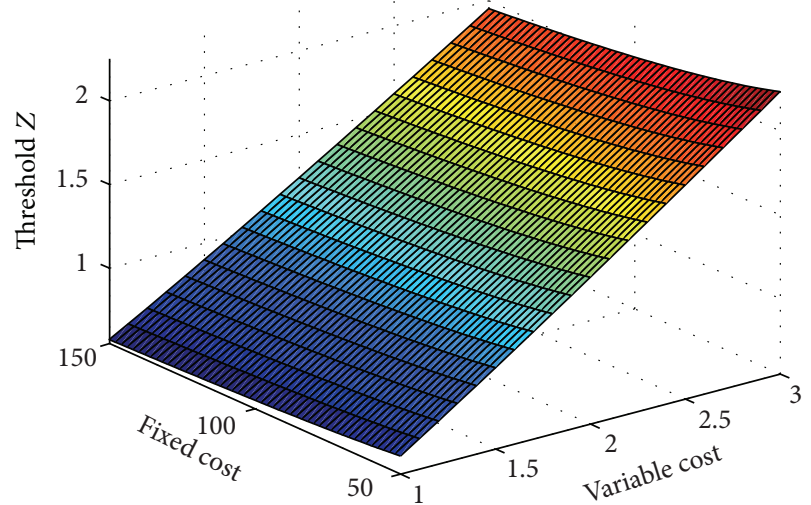

(a)

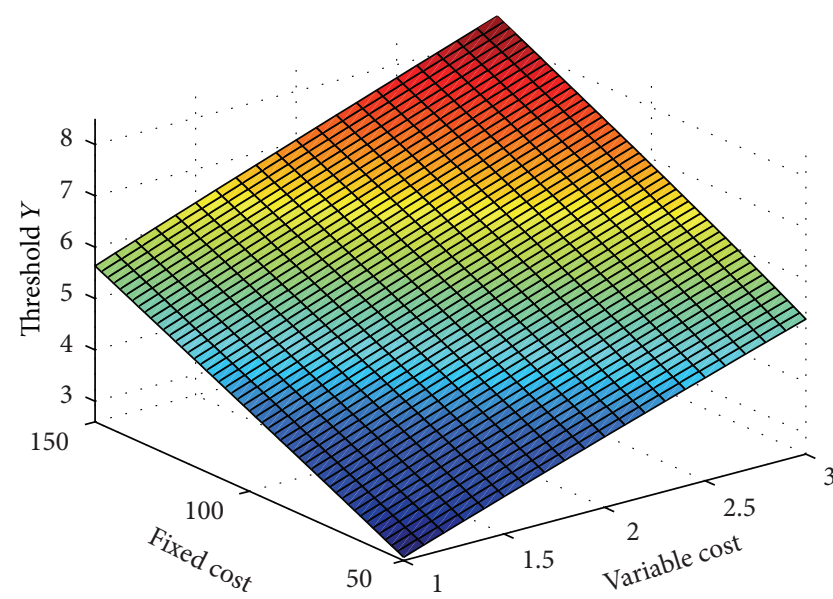

(c)

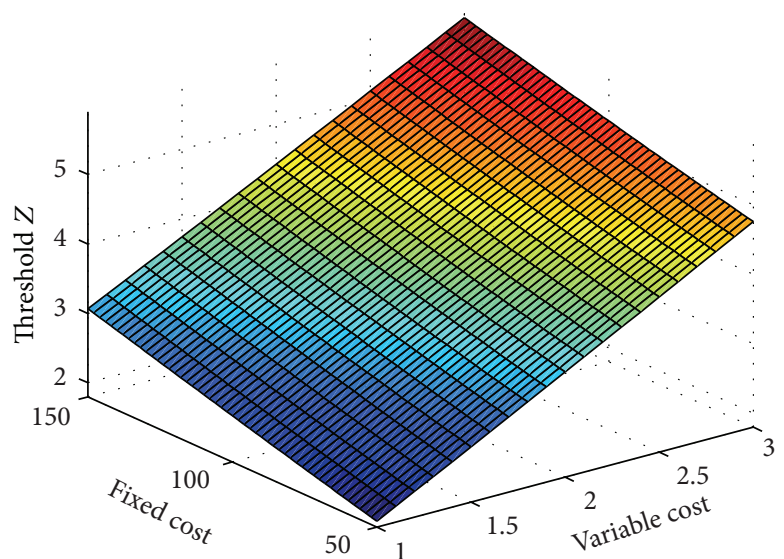

(b)

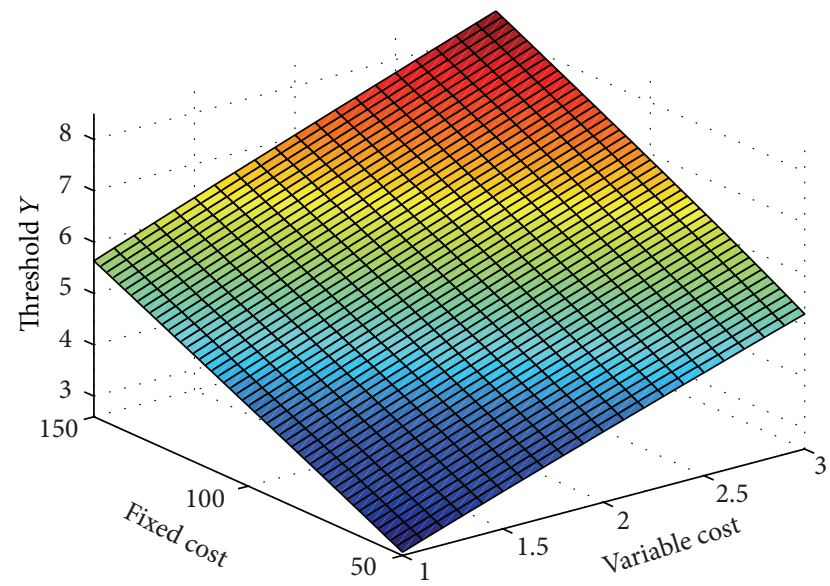

(d)

Figure 8: Dependencies of entry thresholds of leader (a) with and (b) without mothballing options on the cost parameters with model specifications $D(1)=4.00, D(2)=2.50, r=0.05, \mu=0.04, \sigma=0.20$, and $S=7$. Under the same model setup, dependencies of entry thresholds of follower (c) with and (d) without mothballing options on the cost parameters are shown.

which is higher than the prevailing market price for elderly care service (around RMB 36000 Yuan per year from the results of our survey) in major cities in Zhejiang Province, indicating that private investors are reluctant to enter the market. This result may explain the low signing rate of PPP projects for elderly care facilities.

As shown in the numerical examples, we found that introducing mothballing options into the PPP contracts could be very instrumental for the purpose of increasing signing rate of PPP projects in the elderly care service industry. First, mothballing options significantly reduce the entry thresholds of private investors. By allowing private investors to suspend their operation when the market price for elderly care service is unfavorable, government can effectively increase the signing rate of PPP projects. Second, the market parameters affect the elderly care facilities with mothballing options and those without the options differently. When the expected growth rate, $\mu$, of the market is low, the entry threshold is high, and investors tend to stay out of the market. However the entry thresholds increase much slower for facilities with mothballing options than those without the options as the expected growth rate decreases. Similarly, the entry thresholds increase much slower for facilities with mothballing options than those without the options as the market uncertainty, $\sigma$, increases. Third, the elderly care facilities with mothballing options are less sensitive than those without the options as the cost parameters varies unfavorably. The increase of fixed cost and variable cost has less negative effects on the willingness to enter for investors with mothballing options. Fourth, the threshold for leader with mothballing options is inert to the variation of government subsidy for fixed cost, which means that the willingness of the private investor as the leader to enter the market is not affected by the amount of subsidy for fixed cost. Therefore, in the communities currently lacking elderly care service, government can cut the spending for subsidizing fixed cost of the facility without losing too much signing rate.

The analysis of the dependences of thresholds for leader and follower on the market parameters, cost parameters, and subsidy parameters suggests that the signing rate of PPP projects of elderly care facility can be raised by reducing financing cost, decreasing the policy uncertainty of PPP 


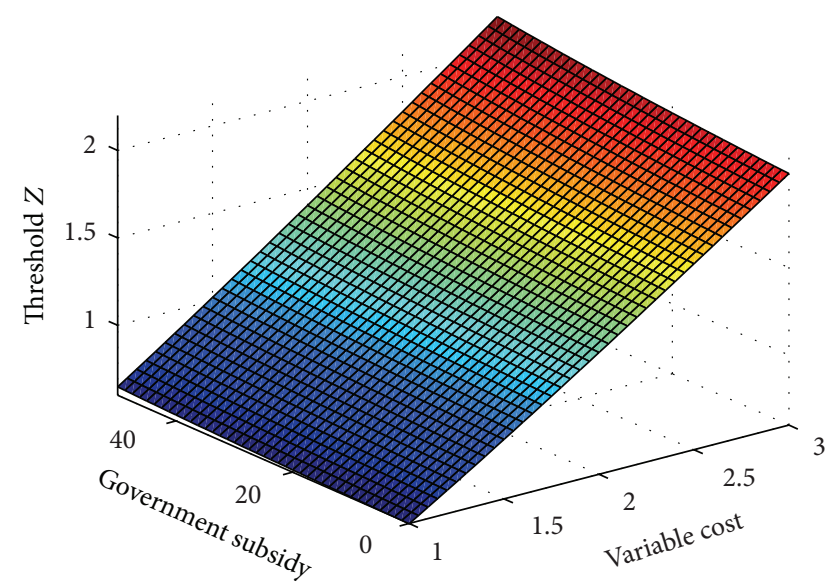

(a)

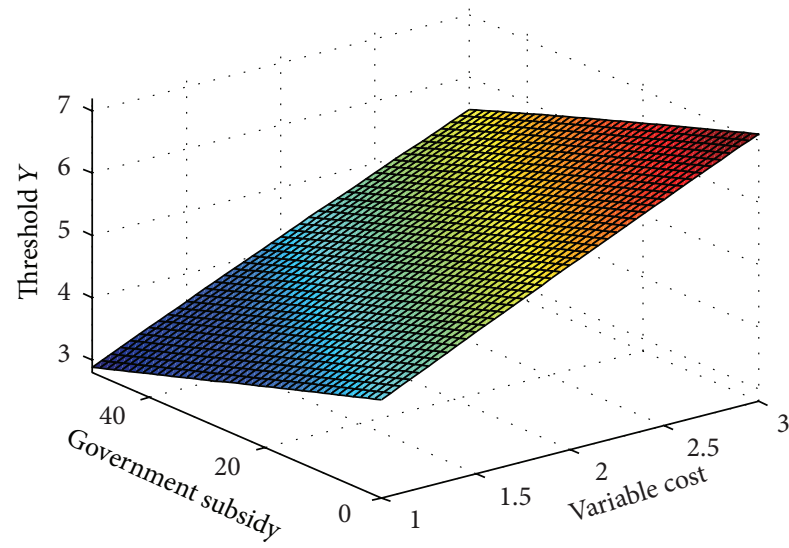

(c)

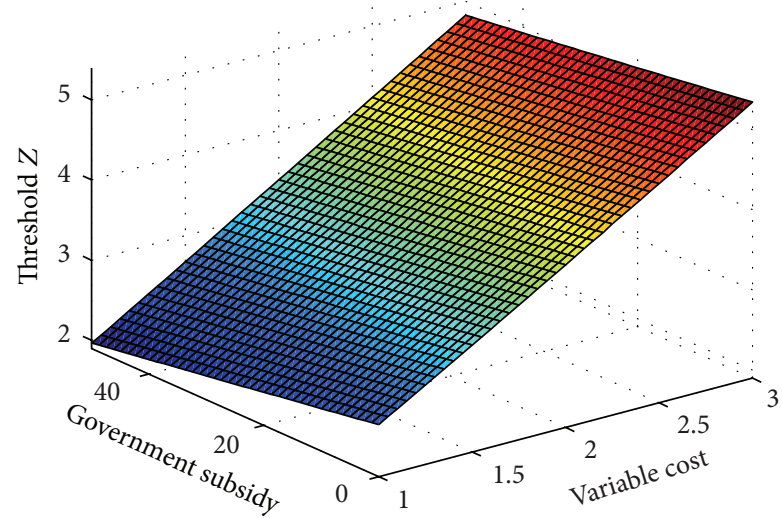

(b)

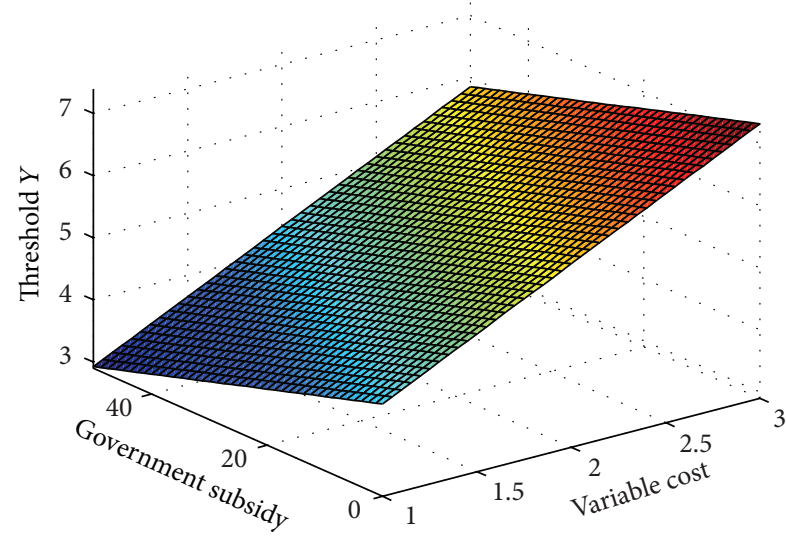

(d)

FIGURE 9: Dependencies of entry thresholds of leader (a) with and (b) without mothballing options on the government subsidy and variable cost with model specifications $D(1)=4.00, D(2)=2.50, r=0.05, \mu=0.04, \sigma=0.20, C=2.00$, and $I=100$. Under the same model setup, dependencies of entry thresholds of follower (c) with and (d) without mothballing options on the market parameters are shown.

projects, and subsidizing elderly care facilities for their variable cost. The volatility in our model consists of two parts: market fluctuation and the uncertainty of government policies. While the market fluctuation is uncontrollable, the uncertainty stemming from changing policies can be contained by government itself. Our study implies that both leader and follower, with or without mothballing option, tend to enter the market sooner, if government policies concerning about PPP projects remain unchanged. Our study also suggests that it is more effective to subsidize the elderly care facilities for their variable cost than for fixed cost in order to increase the signing rate, since the variation of variable cost has much more significant effect on the threshold of both leader and follower than that of fixed cost.

\section{Conclusions}

In this paper, we developed models which enable us to analyze the entry strategies of potential private investors to the elderly care service market with price uncertainty. In a duopoly market setting, the competitions between two private investors without mothballing options and the two investors both in possession of mothballing options were analyzed. The optimal strategies for the private investors were then presented by the entry thresholds of leader and follower into the market. Using numerical examples, we demonstrated that the introduction of mothballing options into the PPP contract significantly reduced the entry thresholds for both leader and follower. We then illustrated the dependencies of thresholds on the market parameters, cost parameters, and subsidy parameter. Specifically, the entry thresholds for the private investors decrease with the increase of expected growth rate and government subsidy and increase with the increase of volatility, discount rate, fixed cost, and variable cost. By comparing the dependencies of thresholds on different parameters, we found that volatility had more significant effect on thresholds than expected growth rate and that variable cost had more significant effect than fixed cost. Based on the results of our study, we suggested the inclusion of mothballing option in the contract of elderly care PPP projects, reducing financing cost, decreasing the policy uncertainty of PPP projects, and subsidizing elderly care facilities for their variable cost. 
Possible extensions of this study include an analysis of competition between one private elderly care facility with mothballing option and the other state owned facility without the option, which is of particular interest, since China now encourages private investment in the elderly care service industry to help with its aging population. Furthermore, we will investigate competition between more than two elderly care facilities and between facilities with options to expand, to contract, and to abandon the underlying projects.

\section{Competing Interests}

All the authors of this paper declare that there is no conflict of interests in connection with the work submitted.

\section{Acknowledgments}

This work is funded by the National Natural Science Foundation of China (nos. 71171176 and 71471161), the Key Program of the National Natural Science Foundation of China (no. 71631005), and Zhejiang Provincial Soft Science Research Program (no. 2014C35040).

\section{References}

[1] F. R. Smets, "Exporting versus FDI: the effect of uncertainty, irreversibilities and strategic interactions," Working Paper, Yale University, New Haven, Conn, USA, 1991.

[2] S. R. Grenadier, "The strategic exercise of options: development Cascades and overbuilding in real estate markets," The Journal of Finance, vol. 51, no. 5, pp. 1653-1679, 1996.

[3] K. J. M. Huisman and P. M. Kort, "Effects of strategic interactions on the option value of waiting," Working Paper, 1999.

[4] S. R. Grenadier, "Option exercise games: an application to the equilibrium investment strategies of firms," Review of Financial Studies, vol. 15, no. 3, pp. 691-721, 2002.

[5] X. Huang and C. Wu, "Option game model of R\&D investment decisions in uncertain environment," Chinese Journal of Management Science, vol. 14, no. 5, pp. 33-39, 2006.

[6] W. Qiu and D. Yu, “Option games model of firm's investment strategy in oligopoly," Journal of Beijing University of Aeronautics and Astronautics, vol. 32, no. 10, pp. 1220-1230, 2006.

[7] T. B. Folta and J. P. O'Brien, "Entry in the presence of dueling options," Strategic Management Journal, vol. 25, no. 2, pp. 121138, 2004.

[8] G. Pawlina and P. M. Kort, "Real options in an asymmetric duopoly: who benefits from your competitive disadvantage," Journal of Economics \& Management Strategy, vol. 15, no. 1, pp. $1-35,2006$.

[9] H. T. J. Smit and L. Trigeorgis, "Valuing infrastructure investment: an option games approach," California Management Review, vol. 2, no. 51, pp. 79-100, 2009.

[10] P. Suttinon, A. M. Bhatti, and S. Nasu, "Option games in water infrastructure investment," Journal of Water Resources Planning \& Management, vol. 138, no. 3, pp. 268-276, 2012.

[11] S. H. Martzoukosa and E. Zachariasb, "Real option games with R\&D and learning spillovers," Management Science and Environmental Issues, vol. 41, no. 2, pp. 236-249, 2013.
[12] R. Takashima, M. Goto, H. Kimura, and H. Madarame, "Entry into the electricity market: uncertainty, competition, and mothballing options," Energy Economics, vol. 30, no. 4, pp. 1809-1830, 2008.

[13] G.-X. Zhang, X.-L. Gao, and Y.-L. Wang, "An asymmetric duopoly investment decision-making model based on difference of option," System Engineering Theory \& Practice, vol. 35, no. 3, pp. 751-762, 2015.

[14] B. Gao, G. Zhang, and J. Guo, "Research on the decision-making in low carbon power generation investment based on mothballing option-with the straw power generation projects as the case study," Journal of Changsha University of Science and Technology (Social Science), vol. 25, no. 6, pp. 50-54, 2010.

[15] X. Lv and T. Shao, "Option game of asymmetric oligopoly," Systems Engineering, vol. 25, no. 12, pp. 23-27, 2015. 


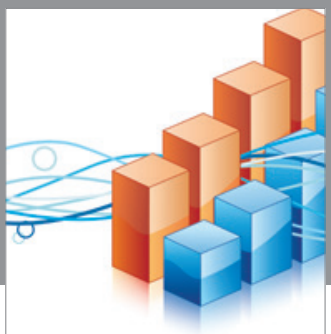

Advances in

Operations Research

vatem alat4

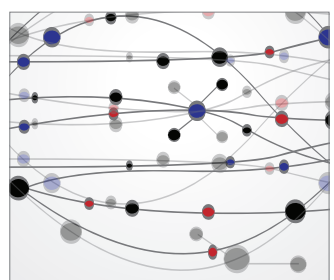

\section{The Scientific} World Journal
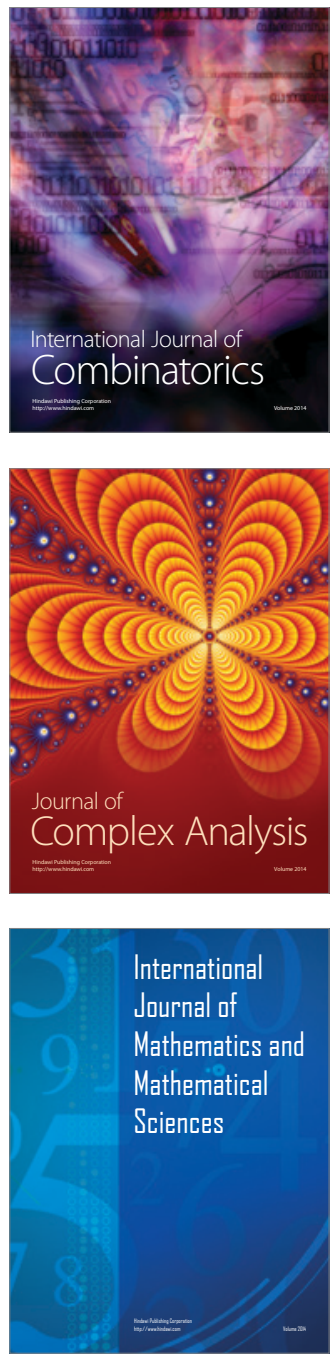
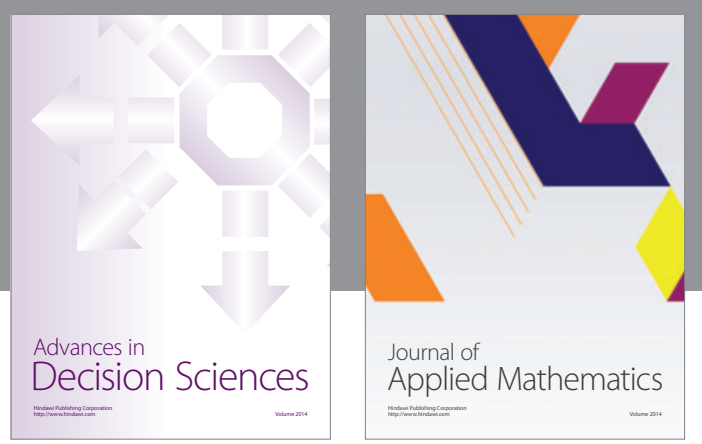

Algebra

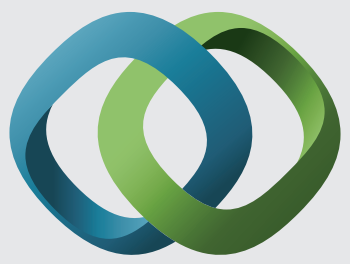

\section{Hindawi}

Submit your manuscripts at

http://www.hindawi.com
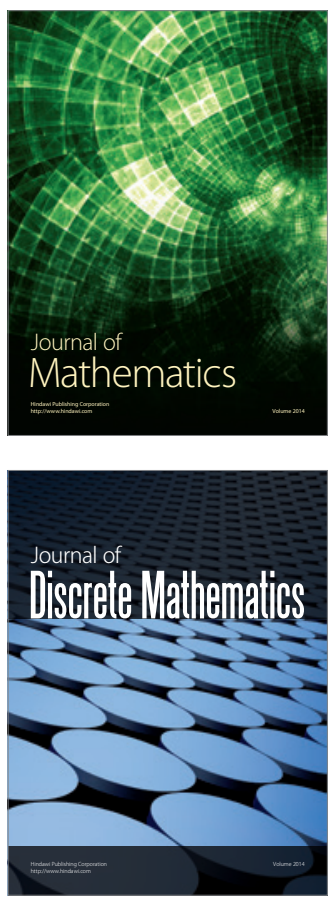

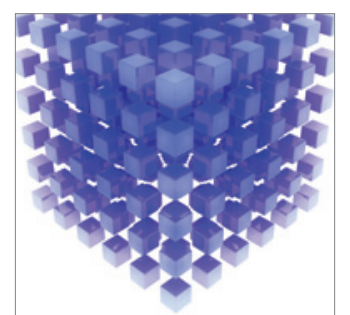

Mathematical Problems in Engineering
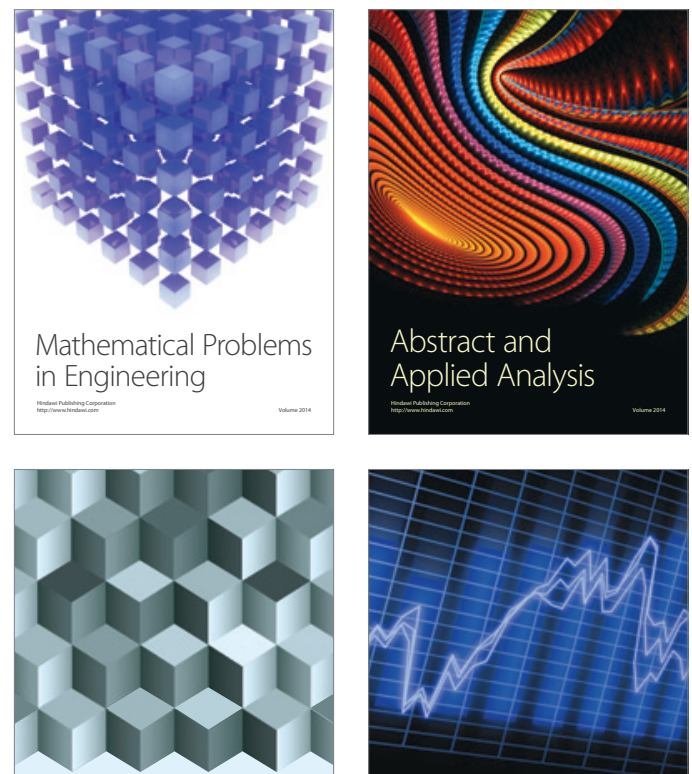

Journal of

Function Spaces

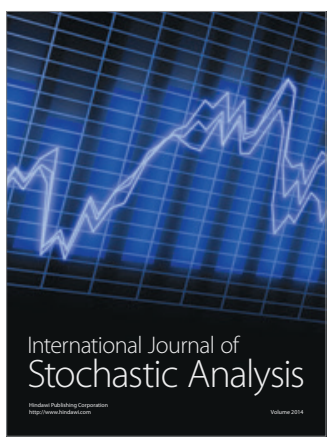

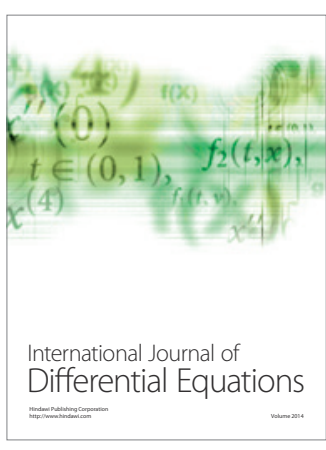
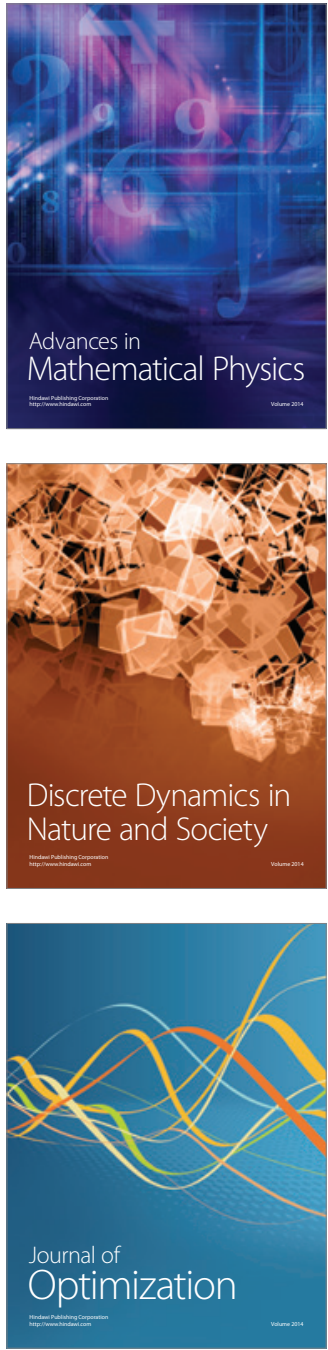